\title{
Erratum to: Barium hexaferrite nanoparticles: morphology- controlled preparation, characterization and investigation of magnetic and photocatalytic properties
}

\author{
Masoud Sadeghi $^{1} \cdot$ Mostafa Ebrahimi $^{1}$
}

Published online: 25 May 2017

(C) Springer Science+Business Media New York 2017

\section{Erratum to: J Mater Sci: Mater Electron}

\section{DOI 10.1007/s10854-017-6747-3}

The original version of this article unfortunately contained a mistake in the Authorship and Results and Discussion section.

It has been corrected with this erratum.

\section{Author and Affiliation:}

Dr. Kheirollah Mohammadi and Dr. Rohollah Azimirad were mistakenly included as authors in the authorship of the article. These two authors have been removed.

The correct authorship is: Masoud Sadeghi and Mostafa Ebrahimi

The affiliation and e-mail address are also corrected with this erratum.
2. Results and Discussion:

(a) The JCPDS Card No. for XRD pattern should be 07-0276 instead of 84-1531. It should be read as JCPDS Card No: 07-0276.

(b) The sample 4 (EDTA as capping agents) used for XRD, FT-IR, VSM analysis, and photocatalytic activity.

The online version of the original article can be found under doi:10.1007/s10854-017-6747-3.

Masoud Sadeghi

M.sadeghi1390@yahoo.com

Islamic Azad University of Arak, Arak, Iran 